\title{
Critical Design Factors of Developing a High-quality Educational Website: Perspectives of Pre-service Teachers
}

\author{
Wing-Shui Ng \\ The Hong Kong Institute of Education, Hong Kong
}

\author{
ngws@ied.edu.hk
}

\begin{abstract}
In the design of a high-quality educational website, little research can be found to consider teachers' point of views in the literature. Teachers are important stake-holders in the educational field. To achieve a more holistic discussion on the issue, a group of 70 pre-service teachers were invited to express their opinions on critical design factors of developing a high-quality website. Results show that web designers should put high emphasis to ease users' browsing experience by providing a good web navigation system. The educational website should also be appealing by appropriately manipulating multimedia elements including color, graphics, fonts and typography. The multimedia learning principles should further be applied to enhance the educational purposes of the website. Among various areas of web design principles, audio was considered as less important in the design of an educational website.
\end{abstract}

Keywords: web design, educational website evaluation, web design guidelines, high-quality website, pre-service teacher

\section{Introduction}

With the development of web technologies, numerous educational websites have been created. Academics also work hard to explore related strategies of making use of websites to support learning and teaching (Lee \& Tsai, 2010). An educational website can be regarded as an electronic platform to store resources for facilitating educational purposes. Whether the presentation of information and the design of website can enhance learning or support teaching is a challenging and important issue. In the literature, quality checkers, criteria, guidelines and principles on web design were suggested to improve the quality of developing general purpose websites (Farkas \& Farkas, 2000; Ivory \& Hearst, 2002; Zaphiris, Ghiawadwala, \& Mughal, 2005). However, the design of an educational website demands further considerations on its unique nature to sup-

Material published as part of this publication, either on-line or in print, is copyrighted by the Informing Science Institute. Permission to make digital or paper copy of part or all of these works for personal or classroom use is granted without fee provided that the copies are not made or distributed for profit or commercial advantage AND that copies 1) bear this notice in full and 2) give the full citation on the first page. It is permissible to abstract these works so long as credit is given. To copy in all other cases or to republish or to post on a server or to redistribute to lists requires specific permission and payment of a fee. Contact Publisher@InformingScience.org to request redistribution permission. port learning. Some studies (C-M. Hsu, Yeh, \& Yen, 2009; Y-C. Hsu, 2006; Hwang, Huang, \& Tseng, 2004; Large, Beheshti, \& Rahman,, 2002; Shee \& Wang, 2008) attempted to explore criteria for designing educational website. However, recommendations suggested from these studies mainly based on opinions from students. Few studies addressed the judgment from teachers. In fact, teachers play a dominant role to 
support students' learning and are always responsible for selecting learning resources, including materials over the Internet, for students. The discussion on creating educational websites is inadequate if opinions from teachers are neglected. According to this line of thought, it is important to put teachers' view into consideration for developing high-quality educational websites. To achieve the purpose, this paper reports a study which was conducted to explore critical design factors of developing a high-quality educational website from teachers' point of view.

\section{Literature Review}

This section attempts to discuss the difficulties concerning the design of an educational website. To follow with, web design principles suggested by academics to create general purpose websites and educational websites are reviewed. The issue arisen on the need to put teachers' views into consideration on educational web design is elaborated at the end of this section.

\section{Difficulties with Educational Web Design}

Many web development tools have been developed as technologies advanced. Commercial software and freeware are available for creating website. Some word processing software also allow users to save contents into web page format. It is no longer a difficult task to create a general purpose website. However, does it mean that people can develop high-quality educational websites to support learning and teaching?

The process of web design demands knowledge and skills in various domains. From communication point of view, a website is an electronic media to convey information. Web designers are required to appropriately integrate words, graphics and other multimedia elements for creating an effective communication with target users. Web designer is expected to have certain level of understanding on communication theory. For example, in Burch's (2001) article, it explored the communications issues in web-based distance education and discussed related web design considerations. Geissler, Zinkhan, and Watson (2001) also conducted a study on web page complexity and further suggested that communication effectiveness is related to web page complexity.

From aesthetic point of view, a website is required to be appealing so as to attract target users to explore the website. It involves the consideration on the use of color, texture, graphics and the design of page layout. Research found that most users' first impression on a website was the impression of beauty (Schenkman \& Jonsson, 2000). During the first few seconds of interaction, users make the decision on whether or not to continue navigating the website (Tractinsky, Cokhavi, \& Kirschenbaum, 2004; Tractinsky, Cokhavi, Kirschenbaum, \& Sharfi, 2006). Lindgaard, Fernandes, Dudek, and Brownet (2006) further stated that these first impressions are constructed in about $50 \mathrm{~ms}$ and remain stable over time. It is also interesting that positive emotional effects brought from beautiful design make users perceive difficult tasks easier to perform (Chawda, Craft, Cairns, Ruger, \& Heesch, 2005, Norman, 2002).

From human computer interaction (HCI) point of view, a website has to be designed in a user friendly format which involves considerations such as web usability, web accessibility and web navigation. Research can be found related to different aspects of HCI considerations in web design (Zaphiris \& Kurniawan, 2007). It includes the analysis of human factors in web design, the HCI design criteria for website and the evaluation of website based on HCI considerations.

In addition, a good web designer is also expected to have sound knowledge on multimedia technology so as to appropriately manipulate multimedia elements in the web design process. It involves the skills and knowledge for manipulating text and typography, editing graphical images as well as controlling audio and video sources. If a website serves educational purpose, the complexity of web design is magnified further with the considerations on the usage of multimedia elements in education (Mayer, 2009; Stemler, 1997), the concept of Technological Pedagogical 
Content Knowledge-Web (TPCK-W) framework (Lee \& Tsai, 2010) and the incorporation of instructional design principles with the World Wide Web (Ritchie \& Hoffman, 1997).

As reflected in this discussion, educational web design can be regarded as a multi-disciplinary project which is not an easy task. A competent web designer is expected to equip knowledge and skills in a lot of domains so as to develop a high-quality educational website. Even though web design software has been developed to simplify the web design technical process in recent years, it is still a challenging task to develop a high-quality website for educational purposes.

\section{General Web Design Principles}

For the sake of helping web designers to develop a high-quality website, some researchers suggested quality checkers, criteria, guidelines and principles on web design. For example, Ivory and Hearst (2002) developed a quality-checker which was similar to grammar-checkers in word processors to help web designer in creating high quality web. Zaphiris, Ghiawadwala, and Mughal (2005) introduced a set of age-centered research-based web design guidelines based on a review of the HCI and aging literature. The U.S. Department of Health and Human Services (2006) published the Research-Based Web Design \& Usability Guidelines with 209 guidelines on different web design aspects. In addition, Farkas and Farkas (2000) suggested 12 guidelines on implementing effective web navigation. The international organization W3C (2008) also published a set of 12 guidelines on web accessibility to improve the quality of web design to cater for the needs of diverse users including those with disabilities. Lots of guidelines or principles suggested in different aspects clearly reflect that web design is a complicated process. It is grateful that many researchers paid efforts on helping web designer to improve the quality of a website. However, these guidelines are mainly for creating general purpose websites which may not be adequate for developing a high-quality educational website.

\section{Web Design Principles for Educational Website}

To address the specific design considerations of an educational website, some studies can be found in the literature which attempted to explore criteria for designing educational websites. For example, scholars, students and web design experts were invited to participate in a study to develop objective criteria for designing web-based learning platforms as well as to develop a reliable and valid scale for evaluating such platforms (Hsu, Yeh, \& Yen, 2009). The study suggested four-dimensional design criteria, namely instructional strategy, teaching material, learning tool and learning interface, comprised 40 indicators for web-based learning platforms. In Shee and Wang's (2008) study, university students were invited in an empirical study concerning a multicriteria evaluation of web-based e-learning system. It suggested that learners regard the learner interface as being the most important dimension of a web-based e-learning system.

Hsu's (2006) study focused on gender-specific preferences of educational website interface design. A total of 56 graduate students participated in the study. Findings of the study suggested that gender is not a factor in considering color value, major navigation buttons placement and navigation mode when designing an educational website. Another study was conducted by Large et al. (2002) to explore the design criteria of web portal for children. Twenty-three children aged between 10 and 13 participated in the study. Results from opinions of children suggested that an ideal portal should cater for both educational and entertainment needs, use attractive screen design with effective use of color, graphics and animation as well as provide search function and subject categories. 


\section{Arisen Issue}

It is undeniable that related studies addressing the design considerations of educational websites allow us to have better awareness on the design of educational websites. However, results from these studies were mainly based on opinions from students who did not receive teacher training. Very few studies can be found to consider the opinions from teachers concerning critical design factors of a high-quality educational website. In fact, teachers play a dominant role to support students' learning and are always responsible for selecting learning resources, including materials over the Internet, for students. As mentioned by Harden and Crosby (2000), a good teacher is more than a lecturer. Responsibilities of a teacher also include the preparation of learning resources and guidance of students' learning. Hwang et al. (2004, p. 66) also stated that students require assistance in selecting proper websites as it is difficult to judge the quality of a website. Since teachers are equipped with sufficient subject and pedagogical knowledge, teacher can provide professional judgments on the appropriateness of the contents in an educational website and the presentation of contents. Thus, a holistic discussion on critical design factors of high-quality educational website can only be achieved if teachers' views are included into consideration.

\section{Research Questions}

With the purpose of exploring the teachers' opinions on the critical design factors of developing a high-quality educational website, this study aims at researching the following question.

"What are the critical design factors of developing a high-quality educational website from teachers' point of view?"

\section{Theoretical Framework}

In order to systematically analyze teachers' opinions on critical design factors for developing a high-quality educational website, a theoretical framework with 3 aspects of web design factors was developed by the researcher. The framework comprises the Multimedia Oriented Aspect, the User Oriented Aspect and the Education Oriented Aspect.

\section{Multimedia Oriented Aspect}

Multimedia elements, such as text, graphics and animation, are foundation building blocks of any web pages. The strategy that multimedia elements are arranged in a website can significantly affect the overall quality. Tutorials on principles of web design usually include chapters on the manipulation of multimedia elements in a webpage (see Beaird, 2010; Farkas \& Farkas, 2002; Sklar, 2012). In this connection, the Multimedia Oriented Aspect which focuses on the considerations of multimedia elements application in a webpage is chosen as one of the aspects in this framework. Areas of web design principles included in the Multimedia Oriented Aspect are listed in Figure 1.

\section{User Oriented Aspect}

Since the ultimate purpose of creating a website is to convey information to users or to facilitate users' online activities, the User Oriented Aspect that focuses on the considerations of target users of the website is proposed. It includes three main areas which are the web usability, web accessibility and web navigation. The concept of usability was grounded in HCI. In Part 11 of the international standard ISO 9241, usability is defined as "the extent to which a product can be used by specified users to achieve specified goals with effectiveness, efficiency and satisfaction in a specified context of use" (ISO, 1997). To extend the concept in educational web design context, an educational website can be regarded as the "product", to support learning and teaching can be regarded as the "goals" of an educational website. Web accessibility refers to the practice of making pages on the web accessible to all users, especially to those with disabilities (Thatcher et al., 
2006). According to Kalbach (2007, p. 5), web navigation refers to "all of the links, labels, and other elements that provide access to pages and help people orient themselves while interacting with a given website". Areas of web design principles included in the User Oriented Aspect are listed in Figure 1.

\section{Education Oriented Aspect}

As the purpose of this study is to explore critical design factors of developing an educational website, the Education Oriented Aspect is therefore included in this theoretical framework. As an educational website usually incorporates multimedia elements to support learning, effective use of multimedia elements to promote learning becomes one of the considerations in educational web design. In this connection, the Multimedia Learning Principles suggested by Mayer (2009) is chosen as one of the web design considerations. In addition, since the design of an educational website involved appropriate integration of subject contents with underlying pedagogical considerations, the concept borrowed from TPCK-W, which is Technological Pedagogical Content Knowledge-Web, proposed by Lee and Tsai (2010) is included in the Education Oriented Aspect of this theoretical framework. It involves the considerations of subject contents and its presentation in web environment with underpinning pedagogical rationales. Figure 1 illustrates the theoretical framework of this study.

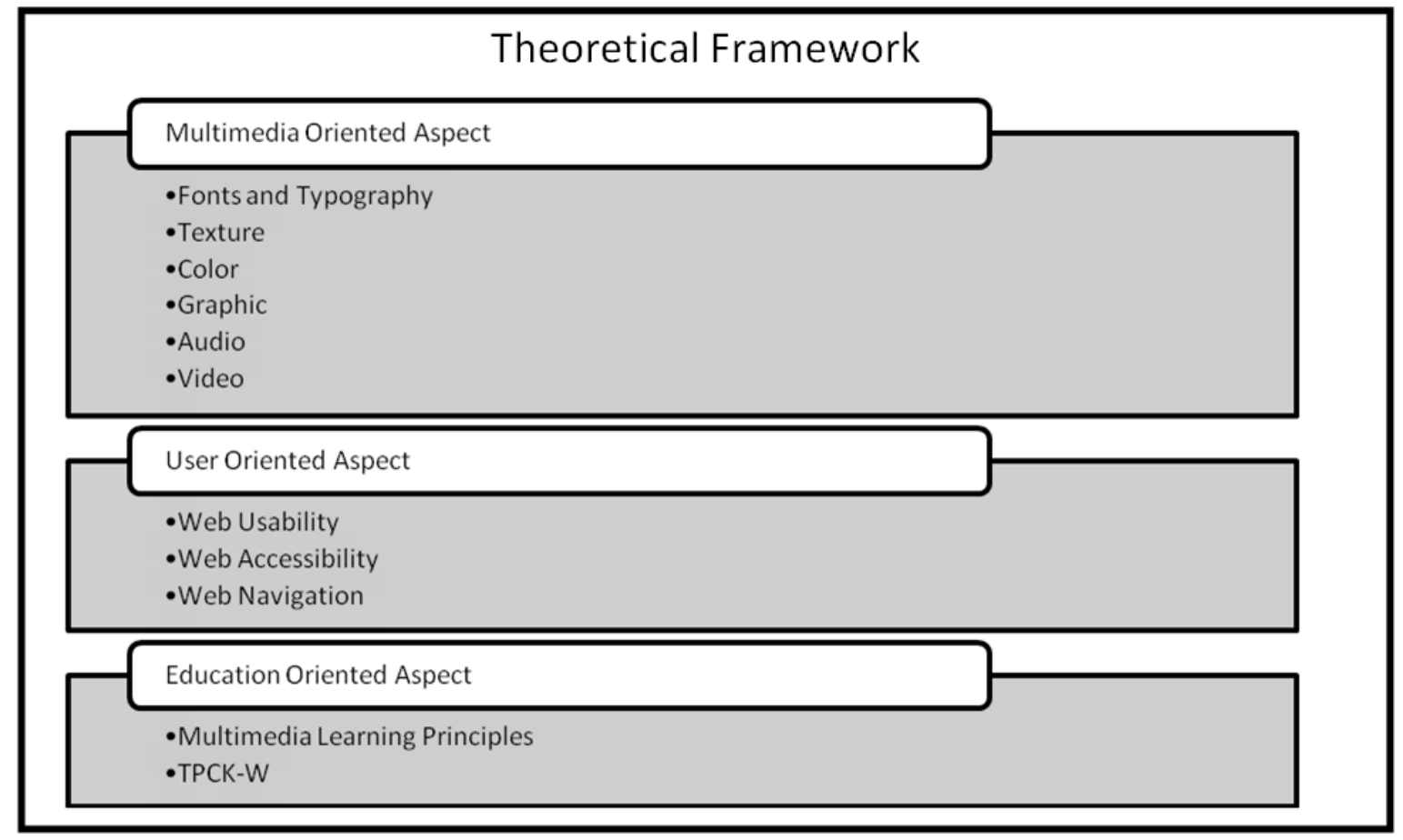

Figure 1: Theoretical framework for exploring critical design factors of developing a highquality educational website from teachers' point of view

\section{Research Design}

The researcher is a teacher trainer in The Hong Kong Institute of Education. This study was conducted in a course entitled Principles and Practice of Web Design taught by the researcher. The course was offered to two classes of first-year pre-service teachers of a bachelor of education programme. The course provided pre-service teachers with principles and concepts for visual design of modern web. It also explored the criteria of web design for meeting specific needs of dif- 
ferent target users. Pre-service teachers had opportunities to critically evaluate websites and to develop high-quality websites with underpinning principles and concepts. A total of 70 preservice teachers taken the course were the participants of the research. They were requested to express their views from the standpoint of a teacher. The course was offered from January to April in 2013. Upon graduation, they are expected to work as teachers in Hong Kong.

In the course, all pre-service teachers participated in this study were required to submit an individual assignment and a group assignment. In the individual assignment, they were required to choose an educational website for critical evaluation on its web design. Amongst various web design principles learnt from the course, they were required to choose those areas of principles that he/she considered as important for evaluating the educational website. They were free to choose any number of web design areas for evaluation. For each chosen principle, they had to evaluate whether the design of the website fulfilled the principle or not. Students were also required to provide supporting evidence in their judgments. In addition to submit an evaluation report, they were required to report which areas of web design principles were chosen to evaluate the educational website.

Concerning the group assignment, pre-service teachers in groups of about 5 were required to develop a high-quality educational website of any topics. A total of 15 groups were formed. They were free to choose any tools for the creation of the websites. Upon completion of the education website, they were required to submit a document to elaborate how web design principles were applied in the development of the educational website. Similar to the individual assignment, each group was also required to report which areas of web design principles were considered as important and were applied in the development of the educational website. In this arrangement, every area of web design principles chosen either in individual assignment for website evaluation or group assignment for website creation can be regarded as a vote from pre-service teachers concerning the critical design factors of designing an educational website.

\section{Results}

Three levels of data analysis were conducted in a step-by-step manner. In the first level analysis, areas of web design principles were compared by the frequencies that were chosen for website evaluation and website creation in their assignments. In the second level analysis, areas of web design principles were grouped into the Multimedia Oriented Aspect, User Oriented Aspect and Education Oriented Aspect respectively for further comparison. In the third level analysis, results obtained from data of website evaluation in the individual assignments were compared with that of website creation in the group assignments to obtain an overall analysis.

\section{Level 1 Analysis}

Results of data obtained from website evaluation in individual assignments are shown in Table 1 and Figure 2. The frequency was subsequently normalized in the range from 1 to 10 for better comparison of their difference. Results show that color was considered as the most important design factor in developing an educational website. In addition, participants also considered that web navigation, graphic, fonts and typography are relatively important in the design of educational websites. On the contrary, audio was considered as the least important factor in an educational website. Moreover, the area of TPCK-W ranked second last in the list which reflects that participants considered this area as relatively less important in the design of an educational website. 
Table 1 : Frequency of web design areas chosen for educational website evaluation

\begin{tabular}{|l|c|c|}
\hline \multicolumn{3}{|c|}{ Critical Design Areas for Educational Website } \\
\hline Design Area & $\begin{array}{c}\text { Chosen for Educational } \\
\text { Website Evaluation } \\
\text { (Frequency) }\end{array}$ & $\begin{array}{c}\text { Normalized Frequency } \\
\text { (range : 1 - 10) }\end{array}$ \\
\hline Color & 49 & 10.0 \\
\hline Web Navigation & 43 & 8.8 \\
\hline Graphic & 41 & 8.4 \\
\hline Fonts and Typography & 40 & 8.2 \\
\hline Web Usability & 27 & 5.7 \\
\hline Video & 19 & 4.1 \\
\hline Web Accessibility & 18 & 3.9 \\
\hline Texture & 15 & 3.3 \\
\hline Multimedia Learning Principles & 14 & 3.2 \\
\hline $\begin{array}{l}\text { Technological Pedagogical Content Knowledge - Web } \\
\text { (TPCK-W) }\end{array}$ & 7 & 1.8 \\
\hline Audio & 3 & 1.0 \\
\hline
\end{tabular}

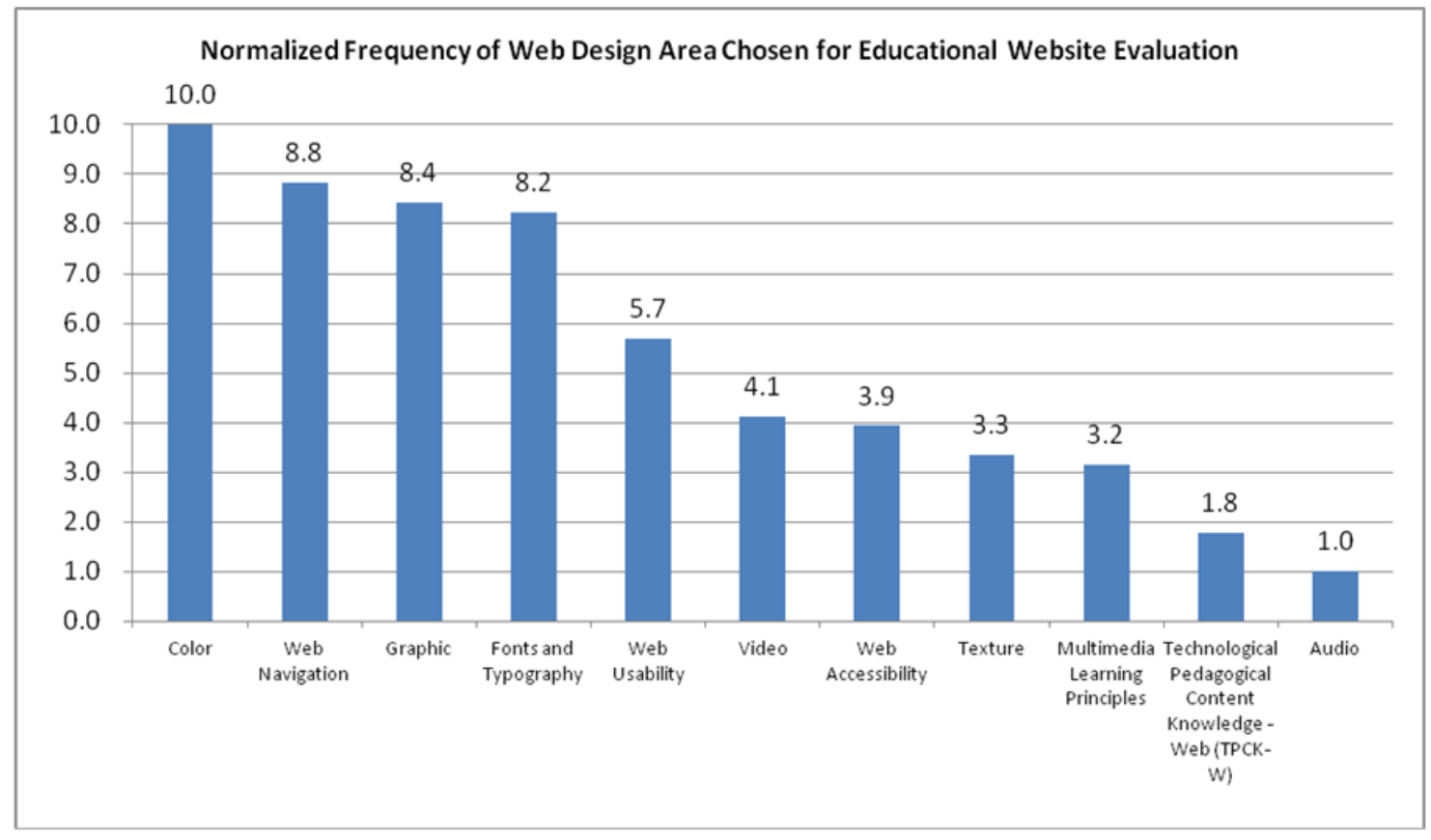

Figure 2: Normalized frequency of web design areas chosen for educational website evaluation

Results of data obtained from website creation in group assignments are shown in Table 2 and Figure 3. Similarly, the frequency was subsequently normalized in the range from 1 to 10 for better comparison of their difference. Results show that color, graphic and web navigation were considered as the most important design factors in creating an educational website. In addition, participants also considered that fonts and typography, video and multimedia learning principles are relatively important in the design of educational websites. On the contrary, audio was consid- 
ered as the least important factor in an educational website. Moreover, the area of TPCK-W and texture ranked second last in the list which reflects that participants considered these areas as relatively less important in the design of an educational website.

Table 2 : Frequency of web design areas chosen for educational website creation

\begin{tabular}{|l|c|c|}
\hline \multicolumn{3}{|c|}{ Critical Design Areas for Educational Website } \\
\hline Design Area & $\begin{array}{c}\text { Chosen for Educational } \\
\text { Website Creation } \\
\text { (Frequency) }\end{array}$ & $\begin{array}{c}\text { Normalized Frequency } \\
\text { (range : 1 - 10) }\end{array}$ \\
\hline Color & 13 & 10.0 \\
\hline Graphic & 13 & 10.0 \\
\hline Web Navigation & 13 & 10.0 \\
\hline Fonts and Typography & 11 & 8.5 \\
\hline Video & 10 & 7.8 \\
\hline Multimedia Learning Principles & 10 & 7.8 \\
\hline Web Usability & 8 & 6.3 \\
\hline Web Accessibility & 8 & 6.3 \\
\hline Texture & 2 & 1.8 \\
\hline $\begin{array}{l}\text { Technological Pedagogical Content Knowledge - Web } \\
\text { (TPCK-W) }\end{array}$ & 2 & 1.8 \\
\hline Audio & 1 & \\
\hline
\end{tabular}

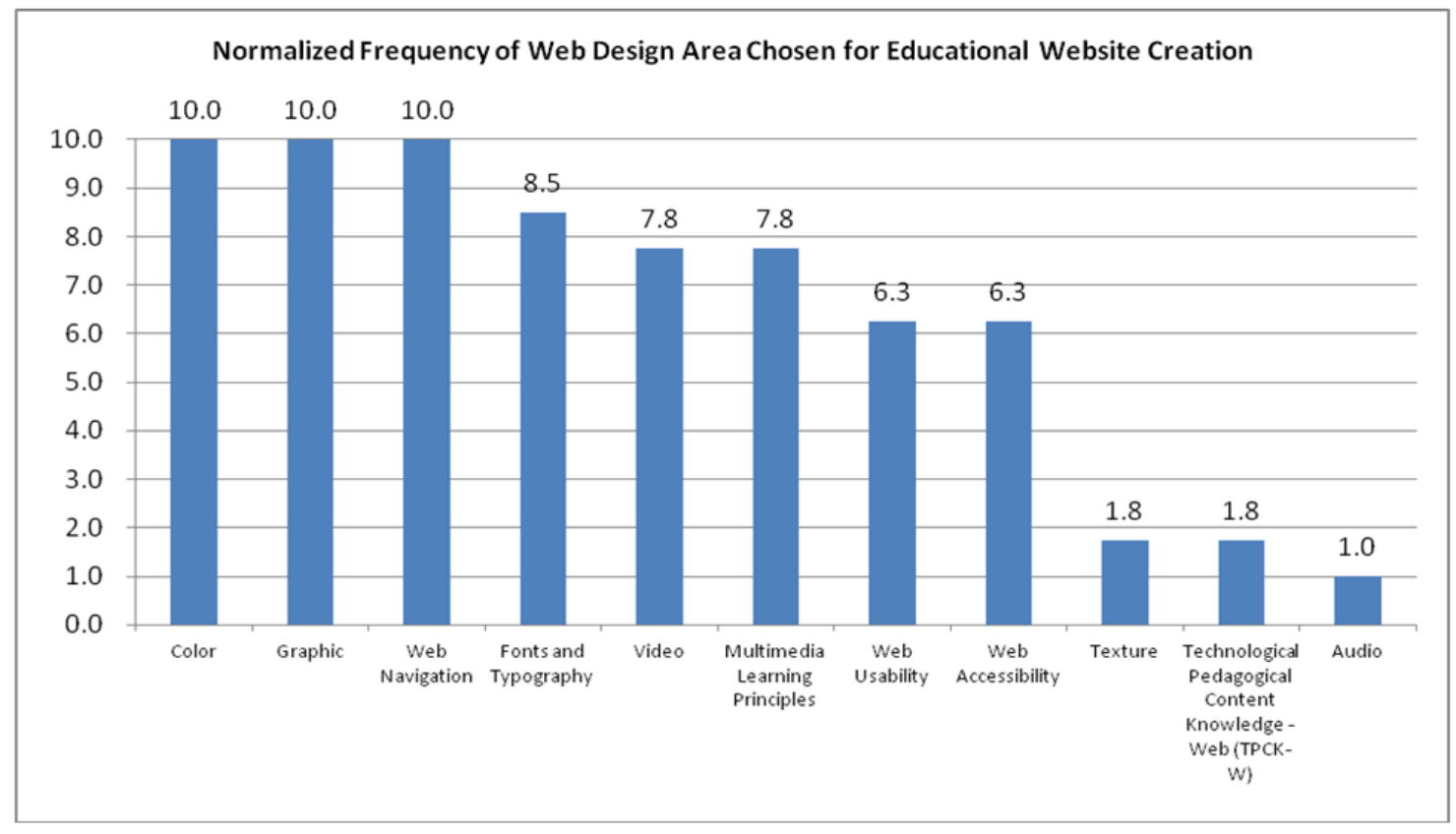

Figure 3: Normalized frequency of web design areas chosen for educational website creation 


\section{Level 2 Analysis}

In Level 2 analysis, data were grouped into Multimedia Oriented Aspect, User Oriented Aspect and Education Oriented Aspect for analysis. Since number of areas in each aspect are different, an average frequency per area of design aspect was computed to achieve a fair comparison.

Results of data obtained from website evaluation in individual assignments are shown in Table 3 and Figure 4. Results show that the highest number of web design areas chosen for evaluating educational websites was under the User Oriented Aspect. It reflects that participants considered the User Oriented Aspect is the most important aspect in educational web design. The Multimedia Oriented Aspect and the Education Oriented Aspect were considered as the second and third important educational website design aspects.

Table 3 : Frequency of web design aspects chosen for educational website evaluation

\begin{tabular}{|l|c|c|c|}
\hline \multicolumn{4}{|c|}{ Design Aspects of Educational Website } \\
\hline Website Design Aspect & $\begin{array}{c}\text { Chosen for Educational } \\
\text { Website Evaluation } \\
\text { (Total Frequency) }\end{array}$ & No. of Areas & $\begin{array}{c}\text { Average Frequency per } \\
\text { Area of Design Aspect }\end{array}$ \\
\hline Multimedia Oriented Aspect & 167 & 6 & 27.8 \\
\hline User Oriented Aspect & 88 & 3 & 29.3 \\
\hline Educational Oriented Aspect & 21 & 2 & 10.5 \\
\hline
\end{tabular}

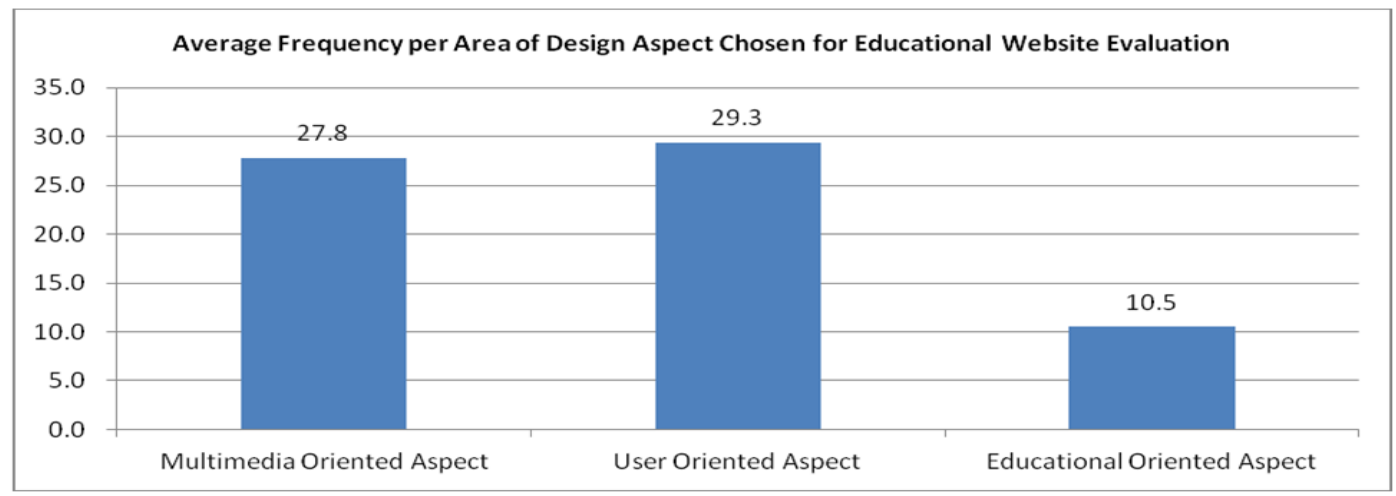

Figure 4: Average frequency per area of design aspect chosen for educational website evaluation

Results of data obtained from website creation in group assignments are shown in Table 4 and Figure 5. The result is similar to that obtained by data from individual assignments. Results show that the highest number of web design areas chosen for evaluating educational websites was under the User Oriented Aspect which reflects that participants considered the User Oriented Aspect is the most important aspect in educational web design. The Multimedia Oriented Aspect and the Education Oriented Aspect were considered as the second and third important aspects of designing educational websites. However, no significant difference was found amongst three aspects. 
Table 4 : Frequency of web design aspects chosen for educational website creation

\begin{tabular}{|l|c|c|c|}
\hline \multicolumn{3}{|c|}{ Design Aspects of Educational Website } \\
\hline Website Design Aspect & $\begin{array}{c}\text { Chosen for Educational } \\
\text { Website Creation } \\
\text { (Total Frequency) }\end{array}$ & No. of Areas & $\begin{array}{c}\text { Average Frequency per } \\
\text { Area of Design Aspect }\end{array}$ \\
\hline Multimedia Oriented Aspect & 50 & 6 & 8.3 \\
\hline User Oriented Aspect & 29 & 3 & 9.7 \\
\hline Educational Oriented Aspect & 12 & 2 & 6.0 \\
\hline
\end{tabular}

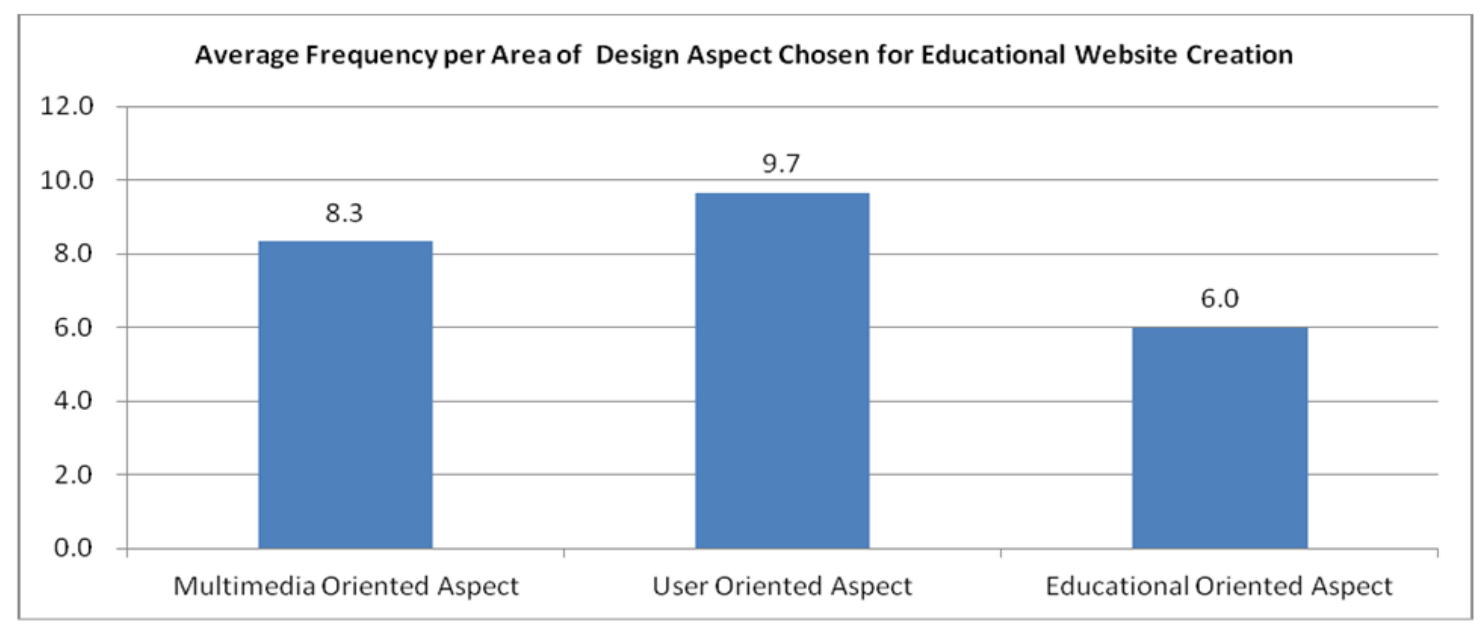

Figure 5: Average frequency per area of design aspect chosen for educational website creation.

\section{Level 3 Analysis}

In the third level analysis, results obtained from data of website evaluation in the individual assignments were compared with that of website creation in the group assignments. As shown in Table 1 and Table 2, all participants considered that color is the most important area in the design of an educational website. Moreover, consistent results obtained in both tables show that graphic, web navigation as well as fonts and typography were also considered as relatively important areas in educational website design. On the contrary, participants, in the process of website evaluation and website creation, considered that audio is the least important web design area. In addition, the TPCK-W area was considered as relatively less important factors in educational website design.

When compared the results in Table 3 and Table 4, consistent results show that participants considered the User Oriented Aspect is the most important aspect in educational website design. The Multimedia Oriented Aspect and the Educational Oriented Aspect were considered as the second and third important aspects in designing an educational website. 


\section{Discussion}

In the research design of this study, opinions of pre-services teachers on critical design factors of educational websites were collected by an individual assignment of educational website evaluation and a group assignment of educational website creation. Participants were requested to seriously engage in the consideration of various areas of web design principles for developing a highquality educational website. Highly consistent results obtained from data of the individual assignment and the group assignment show that the design of the research is of high reliability.

Participants opined that the User Oriented Aspect, particularly the web navigation area, is the most important aspect to be considered in the design of an educational website. It suggests that whether the educational website is usable is very important from teachers' point of view and the design of web navigation is a critical factor in this aspect.

On the other hand, multimedia elements, including color, graphic, fonts and typography, were considered as the most important areas in designing an educational website. It suggests that perservice teachers considered the appearance of an educational website are highly important. They inclined to agree that the first impression of the website determines whether users will continue to further explore the website. These results also echoed the study by Schenkman \& Jonsson (2000) and Tractinsky et al. (2006) that the first impression of beauty on a website affects users' subsequent decision on further browsing the website.

On the contrary, audio was considered as the least important factor of an educational website. It suggests that audio is not a critical factor that can add value to the quality of an educational website. To look into the area of multimedia learning principles in the Education Oriented Aspect in the process of educational website creation, it is found that multimedia learning principles were applied in website creation in a high frequency although less attention was paid on the TPCK-W area. It suggests that participants considered appropriate manipulation of multimedia elements for learning can improve the overall quality of the website for educational purpose.

\section{Conclusion}

To obtain a more holistic discussion on the critical design factors of developing a high-quality educational website, pre-service teachers' opinions were explored systematically. This study suggested some guidelines for web designers to create high-quality educational websites in the future. Web designer should first of all consider the User Oriented Aspect to make the educational website more usable to target users. In particular, the principles on web navigation, such as those suggested by Farkas and Farkas (2000), should be applied in the educational website design. Secondly, web designers should consider the Multimedia Oriented Aspect to improve the overall appearance of the educational website so that users will find it appealing and further explore the educational website. In this aspect, web designer should pay attention to the web design principles in the areas of color, graphic as well as fonts and typography. After considered the user-friendliness and the appearance of the educational website, web designer should pay attention to the Education Oriented Aspect, particularly the multimedia learning principles, to enhance the effectiveness of achieving educational purposes. Moreover, the impact of audio to the quality of an educational website is relatively low. Web designers are recommended to pay less emphasis in manipulating audio in an educational website. Certain limitation existed in this research. In this study, a group of pre-service teachers were invited to participate. They were requested to express their opinions from teachers' point of view with certain level of teacher training. They are expected to work as teachers after graduation. However, since pre-service teachers may have limited teaching experiences, further research could be conducted to explore in-service teachers' opinions or to conduct a longitudinal research to collect participants' opinions after their gradua- 
tion. Although limitation exists, this study has shed light on teachers' opinions on the critical design factors of developing a high-quality educational website which worth future reference.

\section{Reference}

Beaird, J. (2010). The Principles of Beautiful Web Design. Canada: SitePoint Pty Ltd.

Burch, R. O. (2001). Effective web design and core communication issues: The missing components in web-based distance education. Journal of Educational Multimedia and Hypermedia , 10(4), 357-367.

Chawda, B., Craft, B., Cairns, P., Ruger, S., \& Heesch, D. (2005). Do "attractive things work better"? An exploration of search tool visualisations. British HCI Group Annual Conference (pp. 46-51). Edinburgh, UK: The Bigger Picture.

Farkas, D. K., \& Farkas, J. B. (2000). Guidelines for designing web navigation. Technical Communication, 47(3), 341-358.

Farkas, D. K., \& Farkas, J. B. (2002). Principles of web design. London: Longman.

Geissler, G., Zinkhan, G., \& Watson, R. T. (2001). Web home page complexity and communication effectiveness. Journal of Association for Information Systems , 2, 1-46.

Harden, R. M., \& Crosby, J. (2000). AMEE Guide No 20: The good teacher is more than a lecturer - The twelve roles of the teacher. Medical Teacher , 22(4), 334-347.

Hsu, C.-M., Yeh, Y.-C., \& Yen, J. (2009). Development of design criteria and evaluation scale for webbased learning platforms. International Journal of Industrial Ergonomics, 39, 90-95.

Hsu, Y.-C. (2006). Better educational website interface design: The implications from gender-specific preferences in graduate students. British Journal of Educational Technology, 37(2), 233-242.

Hwang, G.-J., Huang, T. C., \& Tseng, J. C. (2004). A group-decision approach for evaluating educational web sites. Computers \& Education, 42, 65-86.

ISO. (1997). ISO 9241: Ergonomics requirements for office work with visual display terminal (VDT) parts $1-17$.

Ivory, M. Y., \& Hearst, M. A. (2002). Towards quality checkers for web site designs. IEEE Internet Computing , 6(2).

Kalbach, J. (2007). Designing web navigation. Sebastopol: O'Reilly.

Large, A., Beheshti, J., \& Rahman, T. (2002). Design criteria for children's web portals: The users speak out. Journal of the American Society for Information Science and Technology, 53(2), 79-94.

Lee, M.-H., \& Tsai, C.-C. (2010). Exploring teachers' perceived self efficacy and technological pedagogical content knowledge with respect to educational use of the world wide web. Instructional Science, $38(1), 1-21$.

Lindgaard, G., Fernandes, G. J., Dudek, C., \& Brownet, J. (2006). Attention web designers: You have 50 ms to make a good first impression! Behaviour and Information Technology , 25, 115-126.

Mayer, R. E. (2009). Multimedia learning. Cambridge: Cambridge University Press.

Norman, D. A. (2002). Emotion and design: Attractive things work better. Interactions Magazine, 36-42.

Ritchie, D. C., \& Hoffman, B. (1997). Incorporating instructional design principles with the world wide web. In B. H. Khan, Web-based instruction (pp. 135-138). Englewood Cliffs, N.J.: Educational Technology Publications.

Shee, D. Y., \& Wang, Y.-S. (2008). Multi-criteria evaluation of the web-based e-learning system: A methodology based on learner satisfaction and its applications. Computers \& Education, 50, 894905. 
Schenkman, B. N., \& Jonsson, F. U. (2000). Aesthetics and preferences of web pages. Behaviour \& Information Technology, 19(5), 367-377.

Sklar, J. (2012). Principles of web design. Boston: Course Technology.

Stemler, L. K. (1997). Educational characteristics of multimedia: A literature review. Journal of Educational Multimedia and Hypermedia , 6(3/4), 339-359.

Thatcher, J., Burks, M. R., Heilmann, C., Henry, S. L., Kirkpatrick, A., Lauke, P. H. ... Waddell, C.. (2006). Web accessibility: Web standards and regulatory compliance. New York: Friends of ED.

Tractinsky, N., Cokhavi, A., \& Kirschenbaum, M. (2004). Using ratings and response latencies to evaluate the consistency of immediate aesthetic perceptions of web pages. Workshop Program \& Proceedings, HCI Research in MIS 04 (pp. 40-44). Washington: AIS SIGHCI.

Tractinsky, N., Cokhavi, A., Kirschenbaum, M., \& Sharfi, T. (2006). Evaluating the consistency of immediate aesthetic perceptions of web pages. International Journal of Human-Computer Studies, 64, 1071-1083.

U.S. Department of Health and Human Services. (2006). Research-based web design \& usability guidelines. Washington: U.S. Government Printing Office.

W3C. (2008, 12 11). Web content accessibility guidelines (WCAG) 2.0. Retrieved 7 29, 2013, from World Wide Web Consortium (W3C): http://www.w3.org/TR/WCAG/

Zaphiris, P., Ghiawadwala, M., \& Mughal, S. (2005). Age-centered research-based web design guidelines. Chi 2005: Technology, Safety, Community: Conference Proceedings: Conference on Human Factors in Computing Systems, (pp. 1897-1900). Portland, Oregon, USA.

Zaphiris, P., \& Kurniawan, S. (2007). Human computer interaction research in web design and evaluation. London: Idea Group Publishing.

\section{Biography}

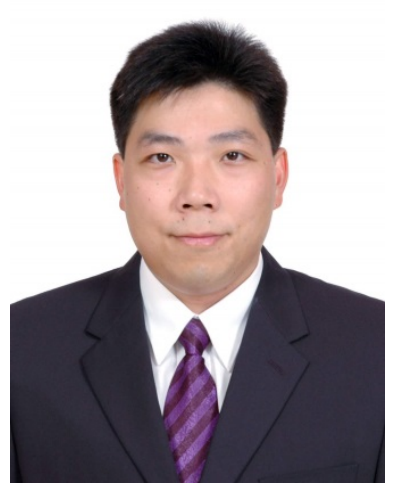

Wing-Shui NG is a teaching fellow in The Hong Kong Institute of Education for training and assessing pre-service and in-service teachers as well as conducting educational research. He has the experience of being seconded to Technology Education Section of Curriculum Development Institute of Education Bureau to develop New Senior Secondary Information and Communication Technology Curriculum, participate in school-based curriculum development, organize teacher training programmes and be invited as a speaker in educational seminars. He also contributed his efforts to serve as a reviewer of Computer Education Textbook Review Panel and a setter as well as marker of public examination papers for Hong Kong Examinations and Assessment Authority. In addition, he was appointed as the School Development Officer in Education Bureau. He also taught Computer Subjects and served as the coordinator in secondary schools for many years. He was the person in charge of Information Technology in Education Committee and a member of School Administrative Council. His research areas include Information Technology in Education and Assessment for Learning. 